\title{
AS MUDANÇAS NA IMAGEM DAS CIDADES DE CURITIBA E FLORIANÓPOLIS: UM ESTUDO SOBRE OS REFLEXOS DA DIVULGAÇÃO DAS CIDADES SEDES PARA A COPA DO MUNDO DA FIFA DE 2014
}

CHANGES IN IMAGE OF THE CITIES OF CURITIBA AND FLORIANÓPOLIS: A STUDY OF THE EFFECTS OF PUBLICIZING THE HOST CITIES OF THE FIFA WORLD CUP 2014

LOS CAMBIOS EN LA IMAGEN DE LAS CIUDADES DE CURITIBA Y FLORIANÓPOLIS: UN ESTUDIO SOBRE LOS REFLEJOS DE LA DIVULGACIÓN DE LAS CIUDADES SEDES PARA LA COPA DEL MUNDO DE LA FIFA DE 2014

\section{Stefanie Fontanete Trotta}

Graduação em Relações Internacionais

stefanie.trotta@gmail.com

Vivian Iara Strehlau

Doutora em Administração de Empresas pela Fundação Getúlio Vargas - SP

vstrehlau@gmail.com

Frederico De Araujo Turolla

Doutor em Economia de Empresas pela Fundação Getúlio Vargas - SP

fturolla@espm.br

Data de Submissão: 06/08/2014

Data de Aprovação: 11/06/2015

Resumo: O objetivo deste trabalho é avaliar a importância da escolha de uma cidade para hospedar um grande evento internacional para imagem desta cidade sede e a manifestação em uma esfera positiva ou negativa, levando em conta a qualificação do teor das notícias analisadas. São analisadas 
as cidades de Curitiba - sede da copa do mundo da FIFA de 2014 e de Florianópolis - cidade para comparativo de pesquisa após o anúncio da escolha da primeira como cidade-sede. Este estudo contém um referencial teórico sobre marca de lugar/destino e megaeventos. Utilizaram-se dois tipos de pesquisa: bibliográfica e documental. Levantou-se a publicação sobre as duas cidades em dois jornais internacionais: o El País e o The New York Times e empregou-se a análise de conteúdo como técnica de análise das informações; em que se classificaram e se analisaram os resultados qualitativos encontrados nessas mídias nos últimos dois anos que antecederam e sucederam ao anúncio. Os resultados indicam que, apesar de haver uma diferença menor no número de artigos encontrados, houve um aumento na avaliação positiva dos artigos, permitindo acreditar que o anúncio trouxe reflexos positivos para as cidades.

Palavras-chave: Megaeventos. Marca de lugar. Imagem de destino. Curitiba. Florianópolis.

Abstract: This study evaluates the importance for the city's image, of being selected to host a major international event, and whether this has a positive or negative effect on the city, based on the qualification of content of the news items analyzed. This work analyzes two Brazilian cities: Curitiba, host of the FIFA world cup 2014, and Florianopolis, a city that was not selected to host the World Cup, and that was used for comparison purposes. This study uses a theoretical framework of place/ destination branding and mega events. We used two types of research: literature review and document analysis. We collected data about the two cities published in two international newspapers: El País and The New York Times. We used content analysis as a technique for analyzing the information gathered, considering two years before and two years after the announcement of which city had been selected to host the event. We categorized and analyzed all the samples, considering both positive and negative aspects of the news. The results indicate that although there is a minor difference in the number of articles found, there was an increase in the positive evaluation of the articles, which led us to believe that the announcement brought positive impacts for the cities.

Keywords: Mega Events. Place branding. Destination image. Curitiba. Florianópolis.

Resumen: El objetivo de este trabajo es evaluar la importancia de la elección de una ciudad que va a hospedar un gran evento internacional para la imagen de esta ciudad sede y su manifestación en una esfera positiva o negativa, tomando en cuenta la calificación del contenido de las noticias analizadas. Se analizaron las ciudades de Curitiba - sede de la copa del mundo de la FIFA de 2014 - y de Florianópolis, ciudad utilizada como comparativo en la investigación, tras el anuncio de la elección de la primera como ciudad sede. Este estudio contiene un marco referencial teórico sobre marca de lugar/destino y megaeventos. Se utilizaron dos tipos de investigación: bibliográfica y documental. Se analizaron las publicaciones sobre las dos ciudades en dos periódicos internacionales: El País y el The New York Times, y se empleó el análisis de contenido como técnica de análisis de las informaciones; de esta manera, se clasificaron y se analizaron los resultados cualitativos encontrados en esos medios en los últimos dos años que antecedieron y sucedieron al anuncio. Los resultados indican que, a pesar de haber una diferencia menor en el número de artículos encontrados, hubo un aumento en la evaluación positiva de los artículos, permitiendo creer que el anuncio trajo reflejos positivos para las ciudades.

Palabras clave: Megaeventos. Marca de lugar. Imagen de destino. Curitiba. Florianópolis. 


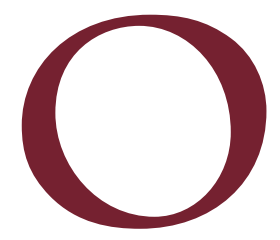

Brasil tem recebido um número crescente de eventos internacionais, sendo que dentre os motivos para o crescimento do número de eventos estão a política de apoio à captação, ao profissionalismo, à imagem do Brasil e à infraestrutura (CARNEIRO, 2011).

Questiona-se o fato da mídia ser considerada uma formadora de opinião e de que forma essas exposições midiáticas afetam as regiões envolvidas nos conteúdos divulgados. Desde a escolha do Brasil como sua sede, a Copa do Mundo da FIFA de 2014 se tornou um assunto recorrente em todos os veículos de comunicação nos discursos políticos, nas discussões acadêmicas e até na conversa da comunidade. A principal importância e preocupação com esse megaevento para o Brasil é o fato de representar uma prova do caráter potencial dos países emergentes, que estão em ascendência na mídia e nas ações transfronteiriças. Houve, desde o anúncio, uma constante preocupação com as críticas sobre o montante e a origem dos recursos dos investimentos, a gestão e a preparação da infraestrutura brasileira para sediar o tão grandioso evento (TAVARES, 2011).

Assim, desde o anúncio da escolha do Brasil como sede desse evento, o mundo passou a analisar, compreender e, eventualmente, criticar o Brasil; houve uma superestimativa ou subestimativa de diversos pontos negativos e positivos que poderim ser desencadeados. Toda a imagem e a estrutura do país são afetadas, até nas áreas menos perceptíveis. Neste sentido, não cabe a discussão sobre se o país deveria ou não sediar a Copa, mas sim analisá-la como um fato, que gera inúmeras consequências e que deve e pode ser analisado e estudado, levando em conta a construção de uma imagem internacional e nas mudanças socioeconômicas e demográficas (TAVARES, 2011). Trata-se, aqui, de avaliar o impacto do anúncio da cidade como sede da Copa sobre esses aspectos.

Para esse trabalho foram escolhidas para a análise duas cidades, sendo elas Curitiba e Florianópolis. Tal escolha é justificada pelo fato de terem semelhanças sociais, econômicas e estruturais, e pelo fato de uma ser sede da Copa do Mundo da FIFA de 2014 (Curitiba) e a outra, uma cidade que não tem vínculos com o evento (Florianópolis). 
O objetivo deste trabalho é avaliar a importância do anúncio internacional para sediar um megaevento na imagem de uma cidade sede e a manifestação em uma esfera positiva ou negativa, levando em conta a qualificação do teor das notícias analisadas. Este trabalho tem ainda, como objetivo específico, o levantamento e a análise dos conteúdos jornalísticos de dois jornais importantes mundialmente sobre Curitiba e Florianópolis e nos períodos de junho de 2007 a junho de 2011.

Toda a análise é comparativa entre uma cidade sede e uma cidade que não está ligada ao megaevento e que pode demonstrar até que ponto as mudanças na imagem e na estrutura da cidade sede estão realmente sendo modificadas pela Copa (IPEA, 2007).

\section{REFERENCIAL TEÓRICO}

Este referencial apresenta dois temas principais: marca de lugar e de destino e megaventos e marca.

\section{MARCA DE LUGAR E MARCA DE DESTINO}

Por bastante tempo, a principal preocupação no tocante ao lugar centrou-se na área de turismo, mas com o passar dos anos tem migrado para as áreas de marketing e negócios (HANNA; ROWLEY, 2008). Os mesmos autores colocam que as pesquisas estão adotando com maior frequência o termo "place" (ou "lugar") e que "destino" refere-se a estudos cujo foco é turismo. Esses autores buscaram uma sistematização de conceitos e destacam que "nação" e "país" têm o mesmo significado e que ambos igualam-se a "lugares" ou "localidades", sendo os dois últimos relacionados também a "cidades", "regiões" ou "distritos".

Hankinson (2005) define destino como um local que uma pessoa tem a intenção de visitar, seja ele turista a lazer ou a negócios, e é um constructo estudado principalmente em seu relacionamento com formação de imagem e branding (BALOGLU; MCCLEARY, 1999; HANKINSON, 2004, 2009; ECHTNER; RITCHIE, 2003; TASCI; GARTNER; CAVUSGIL, 2007). 
A definição de marca, segundo a American Marketing Association (2008), é de que marca é "um nome, termo, sinal, símbolo ou design, ou uma combinação de dois destinados a identificar os produtos e serviços de um vendedor ou grupo de vendedores e para diferencia-los da concorrência". Devido à complexidade da marca, seja em termos acadêmicos, seja na aplicação prática, estes conceitos e definições vêm crescendo muito. Seja esta marca aplicável a um produto, serviço, empresa ou a um destino, um local (KERR, 2006).

A marca de destino pode ser definida como um nome, logotipo, símbolo, palavra ou outro gráfico que tanto a identifica e diferencia o destino, além disso, que transmite a promessa de uma viagem como uma inesquecível experiência que está unicamente associado com o destino; também serve para consolidar e reforçar a lembrança do prazer da memória de experiência no destino. (KERR, 2006, p. 277).

Este conceito de marca e os estudos sobre este tema surgiram da gestão de produtos de consumo (NEBENZHAL, 2004), porém este conceito foi reexplorado e reposicionado podendo, portanto, fora do setor produtivo, ser utilizado muitas vezes não para vender, mas apenas pela imagem (HANKINSON, 2010). Com a evolução do entendimento deste conceito, passou a ser importante a discussão acerca de como esse pode promover um lugar (FETSCHERIN, 2010). Lugares competem por atração de investimentos e turistas e, portanto, princípios de gestão de marcas estão sendo empregados para lugares (KERR, 2006).

Marca de lugares tem sido definida como "a prática de aplicar a estratégia de marca e outras técnicas de marketing e da disciplina para o desenvolvimento econômico, social, político e desenvolvimento cultural das cidades, regiões e países" (KERR, 2006, p. 278).

Um elemento importante da marca é a sua imagem. A imagem que o consumidor terá na mente sobre um local, cidade ou país está diretamente relacionada à soma de valores e percepções que é formada a partir das competências apresentadas. É um mix de elementos que diferenciam um local do outro (ANHOLT, 2005; DINNIE,2008).

Quando um destino procura ser associado a uma marca, denomina-se de marca de destino, que pode ser representada de diferentes maneiras, seja um logo, desenho; algo que represente o que o destino está querendo passar 
para os turistas do mundo inteiro. Deve-se enxergar a marca como um item insubstituível na construção de um valor, seja para uma empresa, produto ou um destino (AAKER, 2007; KELLER, 1993).

Dessa forma, percebe-se que este conhecimento não serve apenas para competir, mas também para reposicionar um destino em uma avaliação cognitiva das pessoas. Os turistas são atraídos a um lugar devido à combinação de atrações, eventos e serviços que lhes oferecem (MOSSEBERG; KLEPPE, 2012).

Os estudos sobre imagem de destino podem ser focados em uma grande dimensão, como na imagem de um país ou um estado; ou em pequena dimensão no que se refere a uma região ou cidade ou mesmo em nível de uma atração (MOSSEBERG; KLEPPE, 2012).

Todas essas esferas citadas podem ser consideradas uma marca e estudadas como tal, pois possuem uma reputação, e buscam pela satisfação e plo reconhecimento do cliente (ANHOLT, 2010); como qualquer marca ou companhia que quer vender o seu produto e a sua imagem (VAN HAM, 2001).

Segundo Echtner e Ritchie (2003), não importa o tamanho da abordagem do estudo da imagem, isto é, seja em grande ou pequena escala, toda imagem pode ser representada por uma estrutura de três componentes bipolares, formando seis possibilidades estruturais: atributo - holístico; funcional/psicológico e comum/exclusivo (MOSSEBERG; KLEPPE, 2012).

Porém o processo de formação de uma imagem deve ser estruturado de forma interativa, para atingir todas as possibilidades de representação, desta forma, a imagem de um local é formada em grande parte nas experiências e nas trocas de experiências das pessoas. Por esse motivo é que o lugar deve oferecer momentos positivos em seus transportes, pessoas, atendimento, eventos, entre outros (SHELDON, 1997; WERTHNER; KLEIN, 1999).

Segundo Crompton (1979), a imagem de um destino que é formada pela "soma de crenças, ideias e impressões que uma pessoa tem de um destino". Já segundo MacKay e Fesenmaier (1997), a imagem de um destino "é composta de vários produtos (atrações) e atributos tecidos em uma impressão total" (MOSSEMBERG; KLEPPE, 2012). 
Porém, esta imagem sempre está ligada à busca por uma representação positiva, ou seja, uma boa imagem interna e externa (GOVERS; GO, 2009).

Há três elementos principais para a compreensão de uma imagem de destino: o contexto em que é definido, a estrutura e o conteúdo. Esta compreensão é a formação de uma marca para o local (MOSSEMBERG; KLEPPE, 2012).

O termo imagem de destino tem inúmeras versões de significados, pois engloba diferentes ideias apresentadas em trabalhos científicos; porém pode estabelecer a imagem de destino como a imagem que o turista constrói em sua mente ao escolher certo local para trabalhar ou viajar (ECHTNER; RITCHIE, 1993).

Na mente do consumidor, a formação de uma imagem de destino pode ser dividida em três momentos: o primeiro momento engloba o indivíduo que nunca teve a intenção ou sequer foi ao destino, mas possui uma imagem formada por fontes, como notíciais comentários de terceiros, cinema, entre outros. O segundo momento já é formado a partir do momento em que o indivíduo tem a intenção de conhecer o destino e está buscando informações, desta maneira pode até ser pelos mesmos meios de pesquisa, mas a atenção dada à informação adquirida é maior. $E$, finalmente, o terceiro momento é a formação das lembranças pessoais que o indivíduo teve ao visitar o destino (FAKEYE; CROMPTON, 1991). A imagem de destino que o indivíduo constrói sobre uma localidade é alimentada frequentemente com informações, opiniões e visitas ao lugar (ECHTNER; RITCHIE, 2003). Em relação ao terceiro momento, a experiência é formada por dois tipos de elementos; os cognitivos, ou seja, a acomodação, a paisagem, os lugares visitados; ou o elemento afetivo, que envolve a hospitalidade, ou seja, como este indivíduo foi recebido no lugar (ECHTNER; RITCHIE, 1993).

O grande desafio da construção da marca de uma cidade, quando se trata de uma exposição como durante a Copa do Mundo, está no fato de ser uma imagem internacional que está sendo formada; cada cultura é impactada e critica de formas diferentes, ainda mais levando em conta que o formador de opinião são os veículos de comunicação, como jornais, revistas e telejornais, dessa forma, cada instituição também transmite a notícia conforme seus protestos e sua cultura (ALMEIDA, 2012). Porém essa imagem também é fortemente afetada, pois depende de que forma o país está lidando com o megaevento, ou seja, este evento irá mexer com todas as esferas, sejam elas sociais, econômicas, 
políticas, de infraestrutura, entre outras. E isso abala muito a opinião pública e mexe com as estruturas políticas. Portanto, o tipo de imagem que será formado depende da maneira de encarar a mudança interna.

\section{MEGAEVENTOS NA ESTRUTURAÇÃO DA MARCA}

Os eventos nas cidades são ferramentas eficazes na formação de uma marca de cidade, pois são fenômenos que em curto prazo trazem interação entre o ambiente e as diferentes pessoas. As impressões e os julgamentos da imagem de uma cidade são como a composição de uma marca de um produto comum, mas estão em constante mudança e seus gestores possuem uma grande dificuldade em controlar e desenhar (GELDERS; ZUILEN, 2012).

Para ajudar na estruturação de uma marca positiva, deve ser trabalhado em longo prazo, ou seja, deve encontrar um órgão que cuide destes eventos e ações que trabalhem de forma compromissada e longa, para se contornar os problemas políticos de ações imediatistas (LODGE, 2002; ANHOLT, 2010), sendo sempre apoiado às decisões oficiais, orçamentos e um programa a ser seguido (RAINNISTO, 2003).

Uma alternativa utilizada pela maioria dos países são os eventos esportivos, pois trazem o sentimento da torcida e do nacionalismo para o local, além de renovar a infraestrutura e os padrões de serviços e locais; também trazem retornos econômicos imediatos (REIN; SHIELDS, 2007). O esporte tem a vantagem de possuir um time, o que reforça a ideia de um grupo que compartilha os mesmos sentimentos e objetivos.

Muitas vezes a duração e o envolvimento da comunidade dependem do número de esferas que o evento irá movimentar no local, ou seja, quanto mais envolver, melhor são os resultados. Assim os órgãos comprometedores devem sempre procurar ações complementares que mexam com economia, cultura, história, política, educação, pessoas, etc. (LALA; ALLRED; CHAKRABORTY, 2009).

Vários trabalhos estudam os refelexos dos megaeventos nas cidades: cidades chinesas têm sido foco de alguns estudos, como o de Wang e Seo (2013), que encontraram o ajuste estratégico e cultural entre a exposição mundial de Xangai 
e a cidade, a qual influenciou de forma positiva a percepção dos turistas diante da cidade, no entanto não necessariamente ocorre uma transferência de uma imagem positiva do evento para a cidade. Os autores destacaram a relevância da comunicação da midia no estudo, mas não aprofundam esse aspecto em suas análises. Por outro lado, Nadeau, O'Reilly e Heslop (2011; 2013) verificaram que a avaliação da China como destino turístico inclui a avaliação do relacionamento da imagem do país com a avaliação dos jogos olímpicos ocorridos em 2008.

Os efeitos de longo prazo também são mais esperados em cidades que unem os eventos a outros fatores, como a qualidade de serviços oferecidos, a infraestrutura, as suas paisagens e as comunicações, como publicidade, slogan, cobertura de mídia, entre outras (GELDERS; ZUILEN, 2012).

Os estudos de Gelders e Zuilen (2012) sobre a cidade de Berlim; e Berkowitz et al. (2007) sobre Beijing, mostram que essas cidades beneficiaram-se do evento em sua imagem. Mas também há relatos que mostram que estes objetivos não foram alcançados, como foi o caso de Rotterdam (GELDERS; ZUILEN, 2012). Muitas vezes o sucesso do efeito de um evento na imagem depende fortemente da forma com que a mídia foi trabalhada (KOTLER et al., 2006).

Foram encontrados poucos trabalhos que tratam da avaliação dos eventos. Zucco, Magalhães e Moretti (2010), por exemplo, estudaram a Oktoberfest, mas são poucos os trabalhos sobre os efeitos dos eventos nas cidades que não sejam fornecidos por meio de profissionais da área diretamente envolvidos no evento. Sant, Mason e Hitch (2014) avaliaram o legado de uma olimpíada de inverno por meio de entrevistas com profissionais reponsáveis pela marca da cidade de Vancouver, no Canadá, bem como seus governantes na esfera local, regional e nacional.

Conclui-se que, em grande parte dos eventos, os efeitos positivos desapareceram após um ano, mesmo recebendo uma forte atenção da mídia. Mas também há que se levar em conta que eventos que foram mais estruturados e que receberam uma gestão que abrangia um plano estratégico de novas instalações, museus, infraestrutura e arquitetura, geraram um impacto positivo e duradouro na mente dos consumidores (GELDERS; ZUILEN, 2012). Por fim, Nadeau, O'Reilly e Heslop (2013) indicam um possível caminho inverso, o de usar uma boa imagem de destino na construção de um evento de grandes dimensões. 
Os mesmos autores dão sequência em outro trabalho, em que destacam o uso de imagens promocionais do lugar em seus materiais promocionais, tais como caráter do país, ambiente construído e competência das pessoas (NADEAU; O'REILLY; HESLOP, 2015).

\section{PROCEDIMENTOS METODOLÓGICOS}

Este trabalho utilizou dois tipos de pesquisa: a bibliográfica e a documental. Para Cervo e Bervian (1983), a pesquisa bibliográfica é uma forma de analisar e estar ciente das contribuições culturais e científicas que já foram feitas anteriormente acerca do assunto; são constituídas por um conteúdo que já foi elaborado, ou seja, contêm a opinião ou a visão do autor do trabalho. $O$ material abrange tudo que já foi publicado em relação ao tema, ou seja: teses, livros, monografias, dissertações, entre outros.

A pesquisa documental tem o mesmo caráter da bibliográfica, porém Gil (1999) destaca que a sua grande diferença está na natureza das fontes, isto é, a pesquisa documental ainda não foi analisada e nem contém a visão de nenhum autor, ela está em sua forma primária. O autor é que irá integrar este material da forma como deseja e interpretá-la para o seu trabalho. O material documental engloba: documentos oficiais, reportagens, cartas, filmes, fotografias, entre outros; ou seja, todo o material que não foi analisado, que se encontra em forma bruta.

Segundo Gil (1999), há dois tipos de material da pesquisa documental, o de primeira mão (não receberam nenhum tratamento analítico), como uma foto, documento, conteúdos midiáticos, etc. E os de segunda mão (já sofreram algum tipo de interpretação), como: tabelas, gráficos, relatórios, etc.

A pesquisa documental foi utilizada no presente trabalho, no formato de conteúdos midiáticos, em que se colheu a informação de primeira mão, sem estar analisada de nenhuma maneira e empregou-se a análise de conteúdo como técnica de análise das informações.

O procedimento adotado foi o método de análise de conteúdo, pois permite tratar e analisar as informações encontradas na mídia, e buscar elementos que possam formar uma imagem de destino das cidades escolhidas (BEDRAN, 2012). 
Segundo Bardin (2009), a análise de conteúdo refere-se a um conjunto de técnicas de análise das comunicações que utiliza procedimentos sistemáticos e objetivos de descrição do conteúdo das mensagens.

A análise de conteúdo é um método de investigação que tem sido muito prático no campo da comunicação, pois é um instrumento que está marcado por uma vasta gama de formas e adaptações para a análise, que envolve conteúdos, como: jornais, revistas, entrevistas, vídeos, etc. Mas esses conteúdos, ao chegar para a pesquisa, devem ser processados para que facilitem a compreensão e a inferência da análise (MORAES, 1999).

\section{SELEÇÃO DO CORPUS DA PESQUISA}

A pesquisa documental deste trabalho é formada pela análise do conteúdo jornalístico. Ou seja, foi colhido material de dois jornais internacionais na busca por conteúdo que demonstrasse a mudança de percepção que as cidades sofreram após a divulgação de estarem dentre uma das cidades-sedes da copa do mundo, em comparação aos anos anteriores.

Inicialmente foram pesquisados os conteúdos do jornal The New York Times, escolhido pela sua importância na comunidade internacional e por ser usado como fonte de notícias para diversos jornais em todo o mundo. O segundo veículo estudado foi o El Pais, importante jornal em língua espanhola.

Neste caso, estabeleceu-se como forma de pesquisa a palavra "Curitiba" e também a palavra "Florianópolis", delimitando os períodos entre junho de 2007 e junho de 2011. Este período foi escolhido devido à data da definição das cidades-sedes, que ocorreu em junho de 2009, representando portanto o espaço de tempo de dois anos anteriores e posteriores ao anúncio. O período foi delimitado em função do momento em que o projeto foi elaborado, em 2012. Portanto, após o anúncio das cidades-sede houve um espaço temporal de dois anos. Para se manter uma equitatividade de período, optou-se por analisar o mesmo período (dois anos) antes do evento, de forma a permitir essa comparação entre dois períodos similares. O mesmo procedimento ocorreu para a cidade de Florianópolis. 
Convém esclarecer que nem todo o conteúdo encontrado foi publicado em formato de papel jornal, a pesquisa englobou todo o conteúdo midiático digital dos dois jornais estudados.

\section{PROCEDIMENTOS DE ANÁLISE REALIZADOS}

Ofundamento da análise de conteúdo está dividido em cinco etapas: Preparação das informações; transformação do conteúdo em unidade; classificação das unidades em categorias; descrição; e interpretação (MORAES, 1999).

No que se refere à pesquisa do conteúdo, foram estudados um total de 123 artigos publicados ou postados, sendo utilizado o Jornal The New York Times e o El Pais, nos períodos de junho de 2007 a junho de 2011. Do total, 59 artigos são provenientes do The New York Times e 64 do El Pais, sendo que 32 fazem referência a Florianópolis e 91 a Curitiba.

O critério de busca do conteúd o foi as palavras-chave "Curitiba" e"Florianópolis", cujas reportagens foram publicadas ou postadas dentro do período citado; porém, do total de 123 artigos, 12 artigos não foram quantificados, pois não apresentou nenhum valor analítico sobre a imagem do local.

Foram utilizadas todas as seções dos jornais, desta forma tem-se um grupo de 10 temas, que englobam assuntos, como: economia, arte, turismo, esportes e muitos outros. Isso devido à importância de todas essas esferas na formação da imagem.

A primeira etapa de análise consistiu em separar e detalhar cada artigo em uma planilha Excel, que continha nome do artigo; subtítulo; autor; dia, mês e ano de publicação; assuntos abordados; e qualificação dos assuntos.

Posteriormente, foi feita uma leitura flutuante para o estabelecimento dos assuntos de cada artigo; para que em uma leitura mais profunda fosse qualificado o artigo entre Positivo 1, Positivo 2, Positivo 3, Neutro, Negativo 1, Negativo 2, Negativo 3, SVA ou ANC. Os procedimentos de análise realizados foram adaptados dos sugeridos por Candeloro (2013), que elaborou uma forma de qualificar os artigos de maneira que a temática pudesse ser classificada como 
positiva, negativa ou neutra, atribuindo notas segundo alguns critérios. Para este artigo, adaptou-se o procedimento sugerido considerando três níveis de avaliação, conforme apresentado no Quadro 1.

Quadro 1: Legenda da Qualificação dos Artigos

\begin{tabular}{|c|c|c|c|c|c|}
\hline & Positivo & Negativo & Neutro & SVA & ANC \\
\hline $\mathbf{1}$ & Positivo quase neutro & Negativo quase neutro & $\begin{array}{c}\text { Apenas cita } \\
\text { o local }\end{array}$ & $\begin{array}{c}\text { Sem valor } \\
\text { analítico }\end{array}$ & $\begin{array}{c}\text { Análise apenas } \\
\text { nos comentários }\end{array}$ \\
\hline $\mathbf{2}$ & Apenas positivo & Apenas negativo & & & \\
\hline $\mathbf{3}$ & $\begin{array}{c}\text { Positivo com exemplo ou } \\
\text { estatísticas }\end{array}$ & $\begin{array}{c}\text { Negativo com exemplo ou } \\
\text { estatística }\end{array}$ & & \\
\hline
\end{tabular}

Fonte: Autor (adaptado de Candeloro, 2013).

Após finalizar esta planilha, todos os assuntos abordados foram organizados em "famílias", ou seja, em temas mais abrangentes, resumindo-se 76 assuntos em 10 temas.

\section{A PESQUISA}

Todos os artigos foram lidos e os assuntos abordados pelos artigos foram indicados e, na sequência, agrupados segundo afinidade em temas conforme indicado no Quadro 2.

Quadro 2: Temas e assuntos

\begin{tabular}{|l|l|}
\hline Cultura & $\begin{array}{l}\text { Cinema; Moda; Arte; Arquitetura; Música; Cultura; Cultura e língua; Fotografia; } \\
\text { Instituto Cervantes; Shows e Exposições. }\end{array}$ \\
\hline Política & Política; Suborno; Eleições; Crime Político; Burocracia \\
\hline Turismo & Estadias; Turismo \\
\hline Esportes & Formula 1; Surf; Copa do Mundo de 2014; Cidades Sedes; Competições; Futebol \\
\hline População & $\begin{array}{l}\text { Brasileiros Lula Oscar Niemeyer População Felipe Massa Guga Amy Winehouse } \\
\text { Doação }\end{array}$ \\
\hline Infraestrutura & $\begin{array}{l}\text { Sistema aéreo Infraestrutura: Correria Inovação Transporte Acomodações Parques } \\
\text { Trafego aéreo Urbanização Linhas aéreas Organização (estrutura das cidades) }\end{array}$ \\
\hline Economia & $\begin{array}{l}\text { Economia Negócios Escritórios Joint Venture Sistema monetário Investimentos Parcerias } \\
\text { Sedes Siemens Câmaras de comércio Tráfico de drogas e economia local Propriedades }\end{array}$ \\
\hline Sustentabildade & Natureza Sustentabilidade Reciclagem Ecologia \\
\hline $\begin{array}{l}\text { Relações } \\
\text { Internacionais }\end{array}$ & $\begin{array}{l}\text { Migração Asilo Político Direitos Humanos Relações Internacionais MERCOSUL } \\
\text { Refugiados no Brasil }\end{array}$ \\
\hline Assuntos Nacionais & $\begin{array}{l}\text { Educação Emprego Catástrofes Naturais Pobreza Segurança Violência Morte } \\
\text { Religião Paz }\end{array}$ \\
\hline
\end{tabular}

Fonte: Autor. 
Em relação à cidade de Curitiba, foram analisados 91 artigos, sendo que 45 são originados do The New York Times e 46 do El País.

Os artigos abordaram todos os temas do universo de 10, porém, observase que há uma maior predominância do tema referente aos aspectos de infraestrutura, conforme se pode observar no Gráfico 1.

Gráfico 1: Quantidade de Artigos por Tema de Curitiba

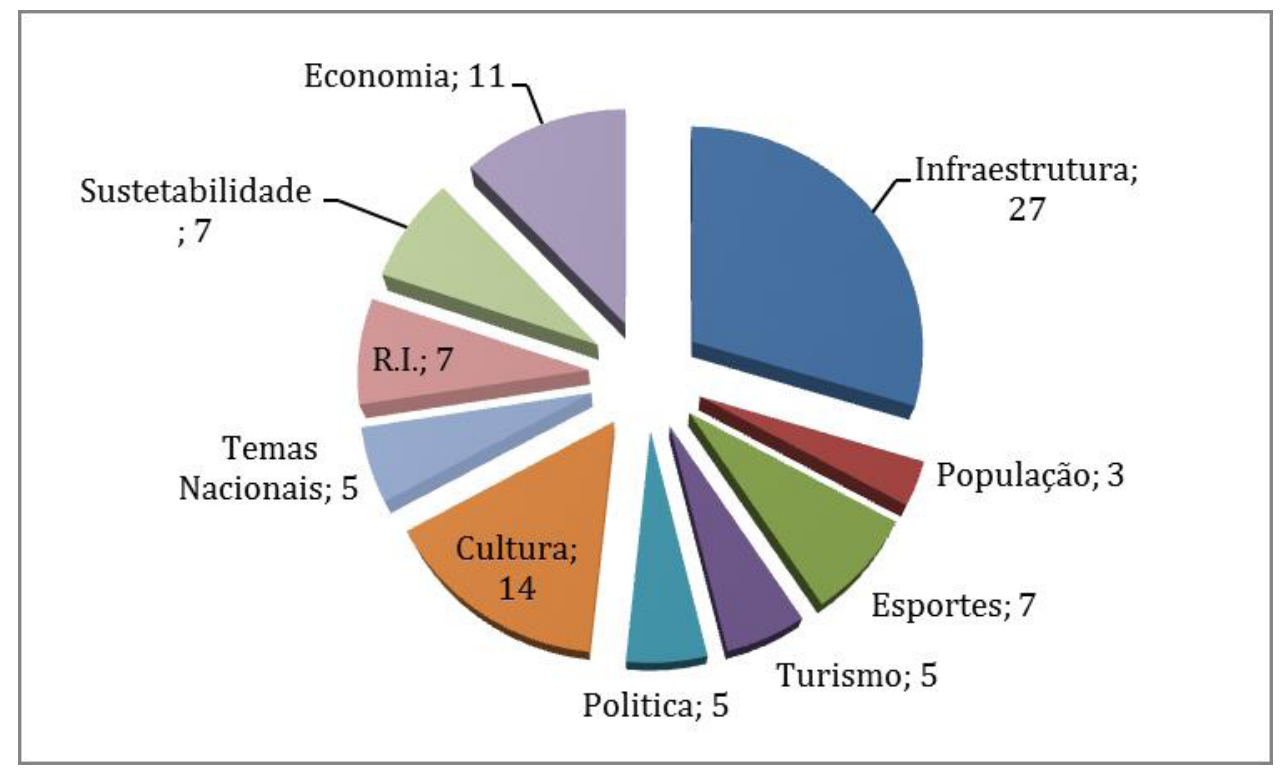

Fonte: Autor.

Em relação à cidade de Florianópolis, foram analisados 32 artigos, sendo que 14 são originados do The New York Times e 18 do El País.

Os artigos também abordaram todos os temas do universo de 10, porém, observa-se que há uma predominância do tema que se refere aos aspectos de cultura e turismo, conforme pode ser percebido no Gráfico 2. 
Gráfico 2: Quantidade de Artigos por Tema de Florianópolis

Fonte: Autor.

O principal foco deste trabalho é a comparação das diferenças em quantidade, qualidade e temas dos períodos de dois anos antes da publicação de quais são as cidades-sede da Copa do Mundo da FIFA de 2014 (junho 2007-junho 2009) e os dois anos após publicação (junho 2009 - junho 2011). Percebe-se que o número de artigos diminuiu após a publicação. Mesmo que sendo uma queda quase insignificante em termos de análise, não se pode ignorar, devido ao fato de o universo ser muito reduzido.

Na análise qualitativa dos períodos, é possível demonstrar a mudança de qualificação dos temas entre o período pré e o pós ao anúncio das cidadessede. Lembrando que são três as categorias: positivo 1 (quase neutro); positivo 2 (apenas positivo); positivo 3 (positivo com exemplo ou estatística).

No tocante à Curitiba, nas colunas referentes ao primeiro período, que antecede ao anúncio, percebe-se que está predominando o positivo 1 e que há um baixo número de artigos negativos. No segundo período, após o anúncio, percebe-se que os artigos positivos do tipo 3 cresceram muito e caíram mais de $50 \%$ do tipo positivo 1 . Pode-se analisar que o número de artigos negativos caiu mais ainda, tornando-se quase irrelevante. O aumento do número de anúncios do tipo 3 traz indicações de melhora na imagem, pois a cidade no primeiro período aparecia nas notícias, porém apenas citada complementando alguma informação (Positivo 1). 
Ao perceber uma evolução do positivo 3 atrelada a uma diminuição dos tipos positivos 1 e negativos, revela que a cidade passou a ser assunto destaque em notícias, sendo exemplo e material de estatística de maneira positiva. Dessa maneira, levando em conta que a imagem de destino na mente do indivíduo é construída frequentemente por meio de informações e opiniões, obter destaque em uma mídia influencia mais essa formação positiva ao contrário de ser apenas citada.

No tocante a Florianópolis, pode-se concluir que sua imagem na mídia é em sua grande maioria positiva; porém, em termos comparativos, possui mais artigos negativos do que de Curitiba, como se observa na Tabela 2. Observa-se que o Positivo 3 predomina na análise, o que é uma indicação relevante para a imagem de Florianópolis. O aumento do número de anúncios do tipo 3 traz indicações de melhora na imagem, pois a cidade no primeiro período aparecia nas notícias, porém apenas citada complementando alguma informação (Positivo 1).

Ao perceber uma evolução do positivo 3 atrelada a uma diminuição dos tipos positivos 1 e negativos, revela que a cidade passou a ser assunto destaque em notícias, sendo exemplo e material de estatística de maneira positiva. Dessa maneira, levando em conta que a imagem de destino na mente do indivíduo é construída frequentemente por meio de informações e opiniões, obter destaque em uma mídia influencia mais essa formação positiva, ao contrário de ser apenas citada.

Tabela 2: Valência dos artigos encontrados por categoria de análise e por cidade

\begin{tabular}{|c|c|c|c|c|c|c|c|c|}
\hline \multicolumn{2}{|c|}{} & \multicolumn{3}{|c|}{ Antes do anúncio } & \multicolumn{3}{c|}{ Após o anúncio } \\
\hline \multirow{3}{*}{ Curitiba } & Tipo 1 & Tipo 2 & Tipo3 & Tipo 1 & Tipo 2 & Tipo3 \\
\hline & Postivos & 17 & 13 & 15 & 7 & 17 & 24 \\
\cline { 2 - 9 } & Negativo & 4 & 6 & 5 & 2 & 2 & 3 \\
\cline { 2 - 9 } & Neutro & 8 & \multicolumn{7}{|c|}{} \\
\hline \multirow{3}{*}{ Florianópolis } & Postivos & 3 & 3 & 8 & 5 & 5 & 8 \\
& Negativo & 3 & 1 & 9 & 1 & & \\
\cline { 2 - 9 } & Neutro & 2 & \multicolumn{7}{|l}{} & 1 & & \\
\hline
\end{tabular}

Fonte: Autor.

$\mathrm{Na}$ análise feita dos artigos das duas cidades, pode-se perceber que alguns temas são predominantes. Por tal motivo, será realizada uma análise dos dois principais temas de cada cidade, sendo: Curitiba, os temas Infraestrutura e Cultura; e de Florianópolis, os temas Turismo e Cultura. 
Tabela 3: Número de Artigo por Tema, por Cidade

\begin{tabular}{|c|c|c|c|}
\hline \multicolumn{2}{|c|}{ FLORIANÓPOLIS } & \multicolumn{2}{c|}{ CURITIBA } \\
\hline Cultura & 13 & Infraestrutura & 38 \\
\hline Turismo & 6 & Cultura & 19 \\
\hline Temas Nacionais & 6 & Economia & 15 \\
\hline População & 4 & Esportes & 10 \\
\hline Política & 3 & Sustentabilidade & 10 \\
\hline Esportes & 3 & Relações internacionais & 10 \\
\hline Infraestrutura & 3 & Política & 7 \\
\hline Economia & 3 & Turismo & 6 \\
\hline Relações internacionais & 3 & Temas Nacionais & 6 \\
\hline Sustentabilidade & 0 & População & 4 \\
\hline
\end{tabular}

Fonte: Autor.

Em relação aos temas abordados, é importante que a cidade tenha um mix de elementos a serem destacados na mídia, pois a formação de valores e percepções é criada por uma soma de diversas competências apresentadas. Ou seja, quanto mais esferas forem apresentadas e desenvolvidas, maior é o impacto na mente do indivíduo. Echtner e Ritchie (1993) destacam a multiciplicadade de elementos que compõem uma imagem de destino e, portanto, quanto mais abrangentes e constantes as informações oferecidas pela mídia, maior o potencial de a cidade ser lembrada e melhorar a imagem atrelada a essa lembrança.

Nota-se que há uma predominância de artigos sobre infraestrutura no caso de Curitiba. Pode-se analisar que grande parte da imagem de Curitiba que é formada internacionalmente vem das inovações que foram criadas para solucionar os problemas de transporte, sustentabilidade e reciclagem. Mudanças que tornaram Curitiba uma cidade exemplo para muitas outras nestes termos e que, constantemente, é comparada a grandes cidades internacionais, como Madrid e Singapura.

Já no caso do tema de Cultura, $100 \%$ dos artigos acerca do tema de Cultura são positivos, o que demonstra que é um bom investimento que as cidades podem realizar para melhorar sua imagem perante os consumidores internacionais.

No caso de Florianópolis, 100\% dos artigos de Turismo são também positivos. No caso de Florianópolis, muitas vezes a sua imagem apenas é vista pelas mulheres bonitas, boas praias e bares, o que faz com que outros aspectos bons 
da cidade acabem sendo esquecidos na imagem no consumidor, devido à falta de exposição desses assuntos pela mídia. Pode-se perceber que os outros temas como Sustentabilidade, Esportes, Economia, Política, entre outros, praticamente não são nem citados nos artigos. Por exemplo, no caso de sustentabilidade, não há artigos sobre Florianópolis que abordem este tema. Trata-se, assim, de um desafio importante da cidade, pois a cidade possui potencial econômico em diversos setores e a concentração em aspectos positivos ligados a turismo não é favorável a uma desconcentração da atividade econômica, bem como à promoção de negócios em outras áreas com alta alavancagem potencial em termos de emprego e renda.

\section{CONSIDERAÇÕES FINAIS}

O principal propósito deste trabalho foi identificar e analisar as mudanças na imagem das cidades de Curitiba e de Florianópolis em função do anúncio da participação na copa do Mundo de 2014 como cidade-sede, comparando com uma cidade que não foi escolhida como sede da copa.

Observa-se que ainda existe uma lacuna de trabalhos que tenham por foco a imagem relacionada a localidades, havendo certa confusão nos conceitos empregados. Megaeventos são comumente associados a mudanças nas cidades que os abrigam. Para que essas mudanças sejam duradouras, é preciso que haja uma boa gestão do processo, bem como grandes investimentos em todos os setores urbanos.

A diferença no número de artigos encontrados para fazer a análise permite acreditarque, apesar de ocorrer uma diminuição no número de artigos apresentados, houve um aumento na avaliação positiva dos mesmos. Quanto à cidade de Curitiba, houve maior retorno na projeção da imagem jornalística ao investir em infraestrutura e sustentabilidade. No entanto, para Florianópolis, a imagem da cidade ainda está fortemente apoiada em turismo, o que não é favorável ao desenvolvimento de uma economia diversificada e à promoção de atividades econômicas não turísticas em que a cidade apresenta potencial importante.

Gelders e Zuilen (2012) apresentam um megaevento como uma ferramenta eficaz para a formação de imagem positiva nas localidades. No caso deste 
trabalho, essa evidência não é muito explícita. Há uma possível fonte de endogeneidade nesse processo: Curitiba já é vista como uma cidade com boa infraestrutura - o que talvez tenha sido o motivo de sua escolha pela FIFA. Talvez o investimento em um megaevento possa trazer uma contribuição em colocar os holofotes da mídia direcionados a um local e, nesse sentido, o incremento em avaliações positivas possa representar uma maior divulgação do que a cidade faz de melhor. Nadeau, O’Reilly e Heslop ( 2015) apontam o uso desse tipo de imagem nos materiais promocionais desenvolvidos para os megaeventos, sendo assim o uso dessas imagens na mídia pode dar suporte e legitimidade ao material promocional que, de outra forma, pode ser visto apenas como um instrumento de persuasão e não de informação.

A maior limitação deste trabalho se deu em função do baixo número de artigos publicados que poderiam ser considerados relevantes. Como sugestão de estudos futuros, caberia um estudo sobre o impacto econômico ou o anúncio de investimentos públicos e privados no período anterior e posterior ao anúncio e também fazer a mesma análise com outro conjunto de cidades.

\section{REFERÊNCIAS}

AAKER, D. A. Construindo marcas fortes. Tradução Maria Lúcia Badejo. Porto Alegre: Bookman, 2007. 344 p.

ALMEIDA, C. O Marketing das Cidades. Gestão e Desenvolvimento, v.12, p. 9-45, 2012.

AMA-American Marketing Association Brand. Disponível em: < http://www.marketingpower. com/_layouts/Dictionary.aspx?dLetter=B>. Acesso em: 16 abr. 2013.

ANHOLT, S. Definitions of Place Branding, Working Towards a Resolution. Place Branding, v.6, n.1, p.1-10, 2010.

ANHOLT, S. Competitive Identity, The New Brand Management for Nations, Cities and Regions. Palgrave Macmillan, Basingstoke, 2007.

ANHOLT, S. Nation Brand as Context and Reputation. Place Branding, v.1, n.3, 2005.

BALOGLU, Seyhmus; MCCLEARY, Ken W. A model of destination image formation. Annals of Tourism Research, v. 26, n.4, p. 868-897, 1999. 
BARDIN, L. Análise de conteúdo. Lisboa, Ed. 70, 2009.

BEDRAN, F. N. O Cosmopolitanismo como Influenciador na Formação de Imagem de Destino, 2012. 171fls. Dissertação de Mestrado. Escola Superior de Propaganda e Marketing, Programa de Mestrado em Gestão Internacional, 2012.

CANDElORO, M. Colombia es Pasion: Modelo de Construção de Marca País. 2013, 217fls. Dissertação de Mestrado. Escola Superior de Propaganda e Marketing, Programa de Mestrado em Gestão Internacional, 2013.

CARNEIRO, L. Política de apoio à captação de eventos internacionais no Brasil: análise do ranking ICCA entre 2003 e 2009. Revista Brasileira de Pesquisa em Turismo. v.5, n.3, p.338-355, dez.2011.

CERVO, A.L.; BERVIAN, P. A. Metodologia Científica. São Paulo, McGraw-Hill, 1983.

CROMPTON, J.L.. Motivations for pleasure vacation. Annals of Tourism Research, v. 6, n. 4, p. 408-424, 1979.

DINNIE, K. Nation Branding: Concepts, Issues, Practice. Oxford: Butterworth Heinemann, 2008.

ECHTNER, C. ; RITCHIE, J. R. B. The measurement of destination image: an empirical assessment. Journal of Travel Research, v. 31, n. 4, p. 3-13, April 1993.

FETSCHERIN, M. The Determinants and Measurement of a Country Brand. International Marketing Review, v.27, n.2, p.164-178, 2010.

GELDERS, D.; ZUILEN, B. V.. City Events: Short and serial reproduction effects on the city's image?, Corporate Communications: An International Journal v. 18, n. 01, 2012.

GIL, Antonio Carlos. Métodos e técnicas de pesquisa social. São Paulo: Atlas, 1999.

GOVERS, R.; GO, F. Place Branding: Glocal, Virtual and Physical Identities, Constructed, Imagined and Experienced. Palgrave Macmillan, 2009.

HANKINSON, G. Repertory grid analysis: An application to the measurement of destination images. International Journal of Nonprofit and Voluntary Sector Marketing, v. 9 n. 2, p. 145-153, 2004.

HANKINSON, G. Destination brand images: a business tourism perspective. Journal of Services Marketing, v. 19, n. 1, 2005. p. 24-32.

HANKINSON, G. Managing destination brands: establishing a theoretical foundation. 
Journal of Marketing Management, v. 25, n. 1-2, p. 97-115, 2009

HANKINSON, G. The Management of Destination Brands: Five Guinding Principles Based on Recent Developments in Corporate Branding Theory. Brand Management, v.14, n.2, p.240-254, 2010.

HANNA, S.; ROWLEY, J. An analysis of terminology use in place branding. Place Branding and Public Diplomacy, v. 4, p. 61-75, 2008.

IPEA. Ensaios de Economia Regional e Urbana, 2007. Disponível em: <http://www.ipea. gov.br/sites/000/2/publicacoes/livros/dirur/ensaios_de_economia_regional_e_urbana/ Abertura.pdf >. Acesso em: 10 set. 2012.

KELLER, K. L. Conceptualizing, measuring, managing customer-based brand equity. Journal of Marketing, v. 57, 1993. p. 1-22.

KERR, G. From Destination Brand to Location Brand. Journal of Brand Management, v. 13, n. 4/5, p. 276-283, apr/jun 2006.

MACKAY, K. J.; FESENMAIER, D.R. Pictorial element of destination in Image formation. Annals of Tourism Research, n.24, 1997, p.537-565.

MORAES, R. Análise de conteúdo. Revista Educação, Porto Alegre, v. 22, n. 37, p. 7-32, 1999.

MOSSBERG, L; KLEPPE, I. Country and Destination Image - Different or Similar Image Concepts? The Service Industries Journal, v. 25, n. 04, p. 493-503, jun 2005.

NADEAU, J.; O'REILLY, N.; HESLOP, L. China's Olympic destination: tourist evaluations of China and the Games. International Journal of Culture, Tourism and Hospitality Research, v. 5, n. 3, p. $235-246,2011$.

NADEAU, J.; O'REILLY, N.; HESLOP, L. A. Linking place, mega-event and sponsorship evaluations. Journal of Product \& Brand Management, v. 22, n. 2, p. $129-141,2013$.

NADEAU, J.; O'REILLY, N.; HESLOP, L. A. Cityscape promotions and the use of place images at the Olympic Games. Marketing Intelligence \& Planning, v. 33, n. 2, p. 147 - 163, 2015. SANT, S.-L.; MASON, D. S.; HINCH, T. D. Conceptualising Olympic tourism legacy: destination marketing organisations and Vancouver 2010. Journal of Sport \& Tourism. v. 18, n. 4, p. 287-312. Nov. 2013.

SHELDON, P. Tourism Information Technology. NY: CAB International, 1997. 
TAVARES, O. Megaeventos Esportivos, Movimento, v. 17, n. 3, p. 11-35, jul/set 2011.

TASCI, A; GARTNER, W.; CAVUSGIL, S. T.. Conceptualization and operationalization of destination image. Journal of Hospitality \& Tourism Research, v. 31, n. 2, p. 194-223, 2007.

VAN HAM, P. The Rise of the Brand State. Foreing Affairs, v.80, n.5, p.2-6, 2001.

WANG, L. Y. C.; SEO, J. Mega event and destination brand: 2010 Shanghai Expo", International Journal of Event and Festival Management, v. 3, n. 1, p. $46-65,2012$.

WERTHNER, $H_{. ;}$KLEIN, S. Information technology and Tourism. A challenging relationship. Vienna, Springer Verlag, 1999.

$\mathrm{XU}$ LI, X.; WANG, Y. Evaluating the effectiveness of destination marketing organizations' websites: evidence from China. International Journal of Tourism Research, v. 12, n. 5, p. 536-549, Sept/Oct 2010.

ZEE, E. van der; GO, F. M. Analysing beyond the environmental bubble dichotomy: how the 2010 World Cup case helped to bridge the host-guest gap. Journal of Sport \& Tourism, v. 18, N. 3, p.161-183, 2013.

ZUCCO, F. D.; MAGALHÃES, M. R. A; MORETTI, S. L. A. Análise do Nível de Satisfação dos Participantes: Evidências das Últimas Três Edições da Oktoberfest em Blumenau (2006, 2007 e 2008). Revista Turismo Visão e Ação, v. 12, n. 3, p. 331-347, set-dez 2010. 